\title{
HOW GESTURE PROVIDES A HELPING HAND AND SUPPORTS CHILDREN'S LANGUAGE ACQUISITION
}

\author{
Ma'rifah Nurmala \\ Lecturing At States Institute Of Islamic Studies -IAIN Palu
}

\begin{abstract}
Children use gesture to refer to objects before they produce labels for these objects to convey semantic relations between objects before conveying sentences in speech. The gestural input that children receive from their or teacher shows that they provide models for their children for the types of gestures and gesture to produce, and do so by modifying their gestures to meet the communicative needs of their children. This article aims to discuss what we know about the impact of gestures on memorization of words. This article describes an explanation the form and example why using gesture would help educator and parent in supports children's language development. More importantly, the gestures that parents and teachers produce, in addition to providing models, help children learn labels for referents and semantic relations between these referents and even predict the extent of children's vocabularies several years later. The existing research highlights the important role parental even the teacher gestures play in shaping children's language learning.
\end{abstract}

Keywords : Children, Language Acquisition, Gesture, Memorize, Speech Combination

\section{INTRODUCTION}

Human language is a remarkable way to communicate. No other form of communication in the natural world transfers so much information in such a short period of time. It is even more remarkable that in three short years a child can hear, mimic, explore, practice, and finally, learn language. There is no genetic code that leads a child to speak English or Indonesia/bahasa or other laguages. Language is learned. We are born with the capacity to make 40 sounds and our genetics allows our brain to make associations between sounds and objects, actions, or ideas. The combination of these capabilities allows the creation of language. Sounds come to have meaning. The babbling sound "ma - ma - ma" of the infant becomes mama, and then mother. In the first years of life children listen, practice, and learn. The amusing sounds of a young toddler practicing language (in seemingly meaningless chatter) is really their modeling of the rhythm, tone, volume, and non-verbal expressions they see in us.

In the early childhood classroom, silence is not golden. Spoken words are opportunities for learning that should take place throughout the day, especially during conversations between children and between teachers and children. The relationship between gesture and 
speech is not entirely understood, but according to Kendon ${ }^{1}$ they are to be considered as two integrated forms of expression that work towards a common goal when produced together. Gestures can provide insight into both child language acquisition and the evolution of language in the human species. There are several theories of the evolution of language; some argue that spoken language evolved from a manual language, others that speech and gesture have been used together from the start. Gestures in child language acquisition have been a topic of interest during the last few decades and in later years there has been a focus on how gestures and speech are used together in children's development. The main focus has been on two types of gesture-speech combinations, complementary and supplementary, and both of these types have been linked to language acquisition. Previous research into the topic of gesture-speech combinations has focused mainly on pointing and other representational gestures.

In the classroom, teachers behave in a specific way: the way they speak and the way they gesture are changed by the classroom situation. They slow down their speech, and they intensify the utterance of every word and of the parameters to make sure that the children will understand them better. For the same reason, they use helping gestures. We are not dealing here with typical everyday communicative gestures but with specific ones, which have to be clear in order to help the children understand the verbal input the gestures illustrate. This is particularly true when teaching to young children. Official and scientific texts dealing with the teaching of foreign languages to children advise teachers to use gestures to illustrate their speech and thus to improve the children's understanding and memorization of the foreign language. This is given as an affirmation and it appeared to us that nobody has ever tried to assess how much the teacher's gestures could help young children understand and memorize the foreign language lexicon.

Language with all of its magnificent complexity is one of the greatest gifts we give our children. Yet, we so often treat our verbal communication with children in a casual way. It is a misconception that children learn language passively. Language acquisition is a product of active, repetitive, and complex learning. The child's brain is learning and changing more during language acquisition in the first six years of life than during any other cognitive ability he is working to acquire. How much easier this learning process can be for children when adults are active participants.

\section{LANGUAGE AND MULTIMODALITY}

Language is multimodal. In interaction, humans use their bodies to make others aware of their intentions, mood, etc. An important part of this is the use of gesture / movements of the hands and the head that are part of what a person is saying. During the twentieth century spoken language has been one main focus of linguistic research, but ever since the 1970s there has been a growing interest in research on other modalities, such as the manual, resulting in a surge in research about gestures. At the same time there was also a rise in the interest in

1 Kendon, Adam 1972a. A review of "Kinesics and Context" by Ray L. Birdwhistell. American Journal of Psychology 85:441-455. 
signed languages. An early description of nonverbal behavior comes from Ekman and Friesen. ${ }^{2}$ They found that nonverbal behavior can be coded according to three major aspects: arbitrariness, i.e. the form of the expression is not linked to its meaning; iconicity, i.e. the form of the act or sign is linked to its meaning so that the meaning becomes apparent from form alone; and intrinsicness, i.e. the act is the same as what it signifies (e.g. hitting someone as an expression of anger). they further categorize five types of nonverbal behavior: emblems (gestures that have a verbal equivalent), illustrators (movements that illustrate the verbal), affect displays (body movements or facial expressions that show emotional states), regulators (movements that regulate the flow of conversation), and adaptors (grooming, flirtation etc.). The present study will approach multimodality from the point of co-speech gestures.

\section{DISCOVERING THE UNITS OF LANGUAGE}

Before infants can begin to map words onto objects in the world, they must determine which sound sequences are words. To do so, infants must uncover at least some of the units that belong to their native language from a largely continuous stream of sounds in which words are seldom surrounded by pauses. Despite the difficulty of this reverse-engineering problem, infants successfully segment words from fluent speech from 7 months of age.

How do infants learn the units of their native language so rapidly? One fruitful approach to answering this question has been to present infants with miniature artificial languages that embody specific aspects of natural language structure. Once an infant has been familiarized with a sample of this language, a new sample, or a sample from a different language, is presented to the infant. Subtle measures of surprise (e.g., duration of looking toward the new sounds) are then used to assess whether the infant perceives the new sample as more of the same, or something different. In this term, we can ask what the infant extracted from the artificial language, which can lead to insights regarding the learning mechanisms underlying the earliest stages of language acquisition.

\section{BASIC STAGES OF LANGUAGE LEARNING}

There are three basic stages in which children develop their language skills.

\section{a. Stage One: Learning Sounds}

When babies are born, they can make and hear all the sounds in all the languages in the world. That's about 150 sounds in about 6500languages, though no language uses all of those sounds. In this stage, babies learn which phonemes belong to the language they are learning and which don't. The ability to recognize and produce those sounds is called "phonemic awareness," which is important for children learning to read.

\section{b. Stage Two: Learning Words}

At this stage, children essentially learn how the sounds in a language go together to make meaning. For example, they learn that the sounds $m$-ah-m-ee refer to the

\footnotetext{
${ }^{2}$ Ekman and Friesen 1972) Linguistics and gesture: an application of linguistic theory.Research Journal.
} 
"being" who cuddles and feeds them, their mommy. This is a significant step because everything we say is really just a stream of sounds. To make sense of those sounds, a child must be able to recognize where one word ends and another one begins. These are called "word boundaries."

However, children are not learning words, exactly. They are actually learning morphemes, which may or may not be words. A morpheme is simply a sound or sounds that have a meaning, like a word mommy/mam.

\section{c. Stage Three: Learning Sentences}

During this stage, children learn how to create sentences. That means they can put words in the correct order. For example, they learn that in English we say "I want a cookie" and "I want a chocolate cookie," not/tidak/jangan", "Want I a cookie/mau kue saya" or "I want cookie chocolate/saya mau cokelat kue". Children also learn the difference between grammatical correctness and meaning. Noam Chomsky ${ }^{3}$ created an example of this difference in the sentence "Colorless green ideas sleep furiously." Children will know that although the sentence is grammatically correct, it doesn't make sense. They know that green is a color and can't, therefore, be colorless.

\section{THE ACQUISITION OF LANGUAGE BY CHILDREN}

The first thing required to acquire a language is a human brain. There is no doubt that human language would not be possible if the human brain was wired up in a different way. The second pre-requisite is they need to acquire language is an environment in which we are exposed to a language. A very famous case that demonstrates the importance of exposure is that of Mc. Gregor ${ }^{4}$. From about 20 months of age, Genie was maltreated by her father. By day she was strapped to a potty and at night she was transferred into a restrictive sleeping bag. She was kept in a bare room with very little to stimulate her senses and she was raised in virtual silence.

In fact her father would beat her if she attempted to produce sounds. When discovered at the age of 13 years, Genie understood only a very few words (mother, walk, go, red, blue, green) and could produce only two phrases (stop it and no more). Because she had not been exposed to human speech in childhood, she had not learnt to talk. In fact, even children with loving parents will not acquire language unless they are exposed to it. Deaf children do not acquire a language unless they have intensive training or are exposed to sign language from early on (in which case, they acquire it as easily as hearing children acquire spoken languages. Although cases such as Genie's show that exposure to language is clearly necessary, there are debates about what type of environment is necessary and about why the environment is necessary. It is indisputable that the amount of speech that children hear can speed up or slow down the language acquisition process. Parents who use more words and who use a greater

\footnotetext{
${ }^{3}$ Chomsky N(1965) Language Acquisition Theory (MIT Press, Cambridge, MA).Google Scholar In book: A Companion to Analytic Philosophy, pp.419-427

4 Karla K. Mc.Gregor (2008) International Journal of Speech-Language Pathology 10(3):112-7 • June 2008 with 443.University of IOWA
} 
variety of different words tend to have children whose vocabulary develops more quickly Greenwood. $^{5}$

The capacity to acquire the ability to incorporate the pronunciation of new words depends upon many factors. First, the learner needs to be able to hear what they are attempting to pronounce. Also required is the capacity to engage in speech repetition. Children with reduced ability to repeat non-words (a marker of speech repetition abilities) show a slower rate of vocabulary expansion than children with normal ability. Several computational models of vocabulary acquisition have been proposed.

Various studies have shown that the size of a child's vocabulary by the age of 24 months correlates with the child's future development and language skills. A lack of language richness by this age has detrimental and long-term effects on the child's cognitive development, which is why it is so important for parents to engage their infants in language If a child knows fifty or fewer words by the age of 24 months, he or she is classified as a latetalker, and future language development, like vocabulary expansion and the organization of grammar, is likely to be slower and stunted

Language acquisition is the process by which humans acquire the capacity to perceive and comprehend language (in other words, gain the ability to be aware of language and to understand it), as well as to produce and use words and sentences to communicate. Language acquisition involves structures, rules and representation. The capacity to successfully use language requires one to acquire a range of tools including phonology, morphology, syntax, semantics, and an extensive vocabulary. Language can be vocalized as in speech, or manual as in sign. Human language capacity is represented in the brain. Even though human language capacity is finite, one can say and understand an infinite number of sentences, which is based on a syntactic principle called recursion

These examples of language learning, processing, and creation represent just a few of the many developments between birth and linguistic maturity. During this period, children discover the raw materials in the sounds (or gestures) of their language, learn how they are assembled into longer strings, and map these combinations onto meaning. These processes unfold simultaneously, requiring children to integrate their capacities as they learn, to crack the code of communication that surrounds them. Once children begin to link words together, experiments using real-time measures of language processing can reveal the ways linguistic and nonlinguistic information are integrated during listening.

\footnotetext{
${ }^{5}$ Charles R. Greenwood Assessing Children's Home Language Environments Using Automatic Speech Recognition Technology. SAGE Journal. Volume 32 Issue 2, February 2011
} 


\section{HOW GESTURES AND SPEECH COMMUNICATION HELP TO LEARN LANGUAGES}

According to Clark and Paivio 6 ,"movements and actions add concreteness and imagery to verbal information and contribute to a better representation and comprehension of knowledge." In How Our Hands Help Us Learn, the authors propose that gestures take away some of the work from learning, leaving our brains to focus on memorizing the vocabulary. They also suggest that gesturing helps to put words into context for the speaker that is specific to his or her world. An individual will have an easier time remembering the word 'walking' after connecting it with a personal memory of physically walking.

Vanessa Van Edwards ${ }^{7}$, an author on human behaviour and a compelling speaker, teaches others on the effective uses of gestures. She summarizes here how using gestures helps with foreign language study. On a side note, we highly recommend visiting her website to learn more about her theories and how you can apply them when communicating with others.

\section{a. Role of child's own gestures in language development}

Children gesture before they speak, they for example, point at an object to draw the adult's attention to that object or to request that object several months before they are able to refer to these objects with words. Importantly, the earlier the child points at a particular object the earlier the same child will produce a verbal label for that object, suggesting a tight positive relation between early deictic gestures (i.e., points) and early words. At the early ages, children also produce two other gesture types, namely conventional gestures that convey culturally agreed upon meanings with prescribed gesture forms (e.g., shaking head sideways to convey negation, extending an open palm next to an object to request the object) and iconic gestures that convey actions and attributes associated with objects (e.g., holding cupped hands to indicate roundness of a ball, tilting cupped hand toward mouth to indicate drinking from a cup). These iconic gestures, even though they are fewer in number compared to deictic and conventional gestures, allow children to convey a greater range of relational meanings (e.g., size, shape, action) than they can do so by using only words.

Gestures than words in their communications, but they also convey a greater meanings with their gestures than with their words. More impressive, children's early gesture use predicts their later spoken language abilities. Children who use greater number of iconic gestures at 19 months of age go on to develop larger verbal vocabularies at 24 months. Similarly, children who convey a greater range of meanings in gesture at 14 months of age show greater verbal vocabularies both at preschool entry at age 4 and at school entry at age 5. Thus the earliest gestures children produce precede and predict oncoming changes in their speech; they both signal the onset of first spoken words and

\footnotetext{
${ }^{6}$ James M.Clark \& Allan Paivio.(1991). Dual coding theory and education.Educational Psychology Review volume 3, pages149-210

${ }^{7}$ Vanessa Van Edwards. (2017) Captivate: The Science of Succeeding with People Published April 25th 2017 by Portfolio
} 
also reliably predict subsequent vocabulary development at the later ages, all the way up to school entry.

After they produce their first words, children continue to use gesture, but now in combination with words (i.e.,gesture+speech). Children initially produce gesture-speech combinations in which the information conveyed in gesture overlaps with the one in speech. Soon after, children begin using gesture-speech combinations in which gesture conveys unique information not found in the accompanying speech, thus allowing them to convey two ideas - albeit across two modalities. Importantly, the age at which children produce their first supplementary gesture-speech combinations predicts the age at which they produce their first two-word combinations. Even after they begin to produce twoword combinations, children continue to use gesture along with speech to convey increasingly complex sentence-like meanings, and these gesture-speech combinations, once again, precede the emergence of similar sentence structures in their speech. For example, the child produces the iconic gesture PUSH while saying 'I play with stroller', thus conveying one action meaning in speech (push) and one in gesture (play) several 5 months before expressing the two action meanings together entirely in speech (e.g., 'I play with stroller by pushing it').

Previous work on typically developing children's gesture production places gesture at the cutting edge of language learning. Gesture not only precedes and predicts on coming changes in speech, but it also develops in conjunction with speech and is often used to convey information that is not easily expressed in speech, particularly during periods of developmental change.

\section{b. Gesture and Language}

Children use gesture to refer to objects before they produce labels for these objects and gesture speech combinations to convey semantic relations between objects before conveying sentences in speech a trajectory that remains largely intact across children with different developmental profiles.

Gesture and language are tightly coupled. In real time, we naturally incorporate gesture as an enhancement to our spoken communication. In developmental time, gesture and language emerge together and develop in parallel It may come as a surprise to hear that speech language pathologists think a lot about gestures. The words "speech language" in our job title sometimes gives the impression that we are focused on how children express themselves verbally. However, a very important part of communication development takes place well before a child says his or her first word -and that is the development of gestures.

Children can begin to use gestures as early as 8 or 9 months of age. Here are some important milestones in the development of gestures at approximately 10 months, children begin to draw attention or point to objects or events first children learn to show (by holding up an object), then give (by giving an object to someone), and finally point (toward a specific object, location, or event). These types of gestures are used before children start to talk. 
Between 9-13 months, children start to make requests using gestures such as reaching with an open-and-closed grasping motion, putting an adult's hand on an object, and pulling an adult's hand towards a desired item or action. Before a child can say 25 words he has usually developed some "iconic" gestures these gestures demonstrate the meaning of the word they represent. Blowing to indicate bubbles or flapping one's arms to represent a bird are examples of iconic gestures. Some iconic gestures are specific to certain cultures, such as thumbs up to mean "good job".

Between 12 and 18 months, children rarely use gestures and spoken words at the same time at around 18 months, children begin to combine gestures and words. The gestures a child uses even before he says his first word tell us a lot about how his communication development is progressing.at first, when children use a gesture and say a word at the same time, both the gesture and the word mean the same thing (e.g. child points to a dog and says "dog"). Soon after, children use a gesture and say a word at the same time, but the gesture and the word mean different things (e.g. child points to a dog and says "big"). When a child starts to use gestures along with a word, but the gesture has a different meaning from the word, this usually means that the child will soon start to combine words. So you can see that the gestures a child uses - even before he says his first word tell us a lot about how his communication development is progressing.

There is a strong link between gestures and speech in communication development. Not only are gestures used before spoken language, but studies have shown that the use of gestures predict when certain language will emerge. For example; children who produce more gestures early on have larger expressive vocabularies later in development. A child who points to or shows an object will likely learn the word for that object within 3 months. Children combine gestures with words before they combine words together. Children who often combine gestures and words together that have different meanings (e.g. point to the dog and say "big") early on are likely to use relatively complex sentences a few years later. Children's gesture use predicts their story telling abilities later on.

Children with expressive language delays have greater language gains when their parents use gestures and words at the same time during interactions with their child. Therefore, gestures and speech go hand-in-hand. By encouraging gestures, you promote your child's overall communication development. Gestures provide a child with a way to express himself before he is able to verbally. And when a child uses a gesture, his listeners respond by saying something about what he has communicated, providing language he can learn from.

\section{GESTURES HELP TO LEARN FOREIGN LANGUAGES}

That's what Giuliana Salvato, Canadian professor of Italian and Second Language Education, suggests. In her book, Looking Beyond Words: Gestures in the Pedagogy of Second Languages in Multilingual Canada, she stresses the importance of gestures in an effective language learning setting and suggests that teachers can use gestures "to clarify concepts, to capture students' attention, and to make a class more dynamic and alive." She 
also advocates that for a learner, gestures help "their reasoning, to convey ideas, and to assist their performance of a task."

Her book is built on numerous studies that suggest gestures are an essential component in acquiring a new language and cite that nonverbal language "improves learning outcomes."Scholars, Macedonia and Kriegstein, review the concept that accompanying foreign words with gestures leads to an easier memorization, in their paper Gestures Enhance Foreign Language Learning. They explain that as far back as the 18th century, it was noted that native language speakers often explain vocabulary to children with the use of images or a gesture in order to help explain what that object is. For instance, when teaching the word piano to a child, one would commonly move the fingers along an imaginary piano. In her other report, Bringing Back The Body Into The Mind: Gestures Enhance Word Learning In Foreign Language, Macedonia mentions a study made by Asher in $1969^{8}$ which firmly states that the memorization of phrases like 'close the door' was greatly improved if learners performed the action while saying the phrase. She cites further studies, made by Zimmer and Quinn-Allen, ${ }^{9}$ which all suggest that gestures enhance the retention of words and phrases and help to avoid the learner from forgetting newly acquired vocabulary.

In the 2008 report, The Effect Of Gestures On Second Language Memorisation By Young Children, Tellier ${ }^{10}$ explains the results of a relevant experiment aimed to see how common vocabulary would be learned by young children with the help of gestures. Half of the group was taught with the help of images; the other half was taught with the support of gestures. The group that was taught with the use of gestures was able to memorize remarkably more of the vocabulary introduced. Tellier concludes that "when reproduced, gestures not only act as a visual modality but also as a motor modality and thus leaves a richer trace in memory." Her literature goes on to discuss yet another experiment conducted in 1998, by Feyereisen, that suggests sentences accompanied by relevant gestures, rather than irrelevant ones, were retained far better by a group of adults. Gestures with verbal can be used both in combination with their verbal equivalent, making that word or phrase more prominent, or without their verbal equivalent, to replace a word or to express something that is not explicit (e.g. that the narrative happened in the past). Gestures can also be used to describe the manner in which a verb is performed, making the utterance more specific in meaning.

\section{ENCOURAGING CHILDREN USING GESTURES}

Use gestures that demonstrate the meaning of the word is the the most helpful for learning words are those that show the shape or function of the object. For example, holding your hands in the shape of a ball while we say "ball" or doing a throwing action while we say "ball" are helpful gestures.

\footnotetext{
${ }^{8}$ James J. Asher. San Jose State College. Search for more papers by this ... First published: January 1969.

${ }^{9}$ Quinn-Allen (1995) conducted the first empirical study on the influence o and Engelkamp and Zimmer (1985) attributed the enhancement to the language in Gretchen M. Reevy, .Stanley N - 2015 - BurstenPsychology

${ }^{10}$ Tellier, M. (2005). How do teacher's gestures help young children in second language acquisition?. Research gate Publication
} 
Be sure to use the gesture and the word at the same time. This helps reinforce the meaning of the word for children. Using simple gestures while you talk with children throughout the day will help build his communication skills. When children use a gesture, acknowledge it by copying it and saying the word that matches the gesture. Make gestures part of everyday interactions with children. There is no special time or place needed to use gestures with the children. Using simple gestures while we talk with our children throughout the day will help build his communication skills.

The information above relates to natural gestures, is fully helpful and recommended for the teacher that will teach language or new language to young ages. In pre-school teacher has the rule and remain use attractive ways to introduce new word related to the material that submitted in their book

\section{TEACHING GESTURE}

In the field of language teaching, speakers produce gestures rather unconsciously to help them structure their thought and organize their words. When the learners are beginners and/or children, the gestures are what the learners rely on to understand what the teacher says. This means that the gestures need to convey enough meaning to be understood alone without verbal language and have to help one to infer the meaning of the words they are associated with. Therefore teaching gestures are produced more consciously than usual communicative gestures and that they are specifically addressed to the learners. There are different types of teaching gestures which appear in class and it discovered in various functions. So far there are three main roles for teaching gestures: management of the class (to start/end an activity, question students, request silence, etc.), evaluation (to show a mistake, correct, congratulate, etc.) and explanation (give indication on syntax, underline specific prosody, explain new vocabulary, etc.).

The gestures which occur in the process of explaining new or unknown vocabulary. They appear in various shapes: hand gestures, facial expressions, pantomime, body movements, etc. They can either mime or symbolize something and they truly help the learners to infer the meaning of the verbal, providing that they are unambiguous and easy to understand. However, teaching gestures do not only help in the process of understanding.

Previous work on the impact of gestures on memorization relied on the following studies to elaborate the present experiment. The first experiment is one elaborated by Cohen and Otterbein ${ }^{11}$ (1992). They worked with three groups of adult subjects. The subjects had to watch a video containing several different sentences, then write down as many sentences as they could remember. Each group had the same sentences but the videos were slightly different: one just exposed the sentences, another one showed somebody illustrating each sentence with illustrative/pantomimic gestures and in the last one, sentences were also accompanied with gestures but they were non-pantomimic. Cohen and Otterbein wanted to assess what modality would help the subjects remember the greatest number of words.

\footnotetext{
${ }^{11}$ Cohen, R. L., \& Otterbein, N. (1992). The mnemonic effect of speech gestures: Pantomimic and nonpantomimic gestures compared. European Journal of RL Cohen - 1992
} 
The illustrative gestures proved to be the most significant helping modality in short term memorization. It has been explored the same objective but in the field of second language learning. She worked with 112 university students in French. A non-treatment group and a comparison group were shown 10 French sentences and their English equivalent on a screen and they also heard a teacher pronouncing them 3 times. They were told to repeat them. The experimental group's procedure differed only in that the students were also provided with an illustrative gesture for each sentence, which they saw three times (with the three repetitions of the sentence) and had to reproduce. However, they did not repeat the sentences, only the gestures. Then, immediately after all 10 sequences, a posttest was given: the teacher said the 10 French sentences in a different order and during the pause after each sentence the subjects had to write down the English equivalent. The comparison group and the experimental group were given the gestures as well. There were 5 sessions of this kind with different groups of 10 French expressions. The analysis of the results shows that the students presented with illustrative gestures recalled more sentences than the others. The experimental group who reproduced the gestures did better than the comparison group who just saw them during the posttest. Both experiments dealt with adult subjects. In our study on second language teaching to young children and the role of teaching gestures in lexical memorization, it seemed interesting to elaborate similar experiments with younger subjects.

\section{CONCLUSION}

According to the theories of language acquisition, therefore we can assume that the use of teacher's gestures in the learning of foreign vocabulary can have an effect on memorization, but to make the most of this effect, teachers should make sure that the children reproduce the gestures while repeating the words. Thus, they will be more active in their repetition and reinforce its trace in memory. It consider important that the impact of gestures in language acquisition should be promoted in teacher's training. Reflection on gestures in teaching language learning as well as development of teaching gesture techniques should be part of teacher's training so that the majority of gestures can be made by learners, especially young ones. ${ }^{12}$ Secondly, it shows that the gestures that the adults working with children themselves produce can influence children's language learning trajectory, by providing models and having an effect on children's own gesture production an important finding that highlights the importance of using gesture as a teaching tool to help children learn a new concept or language ability.

\footnotetext{
12 Goldin-Meadow, S. (2000). Beyond words: The importance of gesture to researchers and learners. Child Development, 71, 231-239.
} 


\section{REFFERENCES}

Chomsky N. 1965. Language Acquisition Theory (MIT Press, Cambridge, MA).Google Scholar In book: A Companion to Analytic Philosophy, pp.419-427

Charles R. Greenwood .Assessing Children's Home Language Environments Using Automatic Speech Recognition Technology. SAGE Journal. Volume 32 Issue 2, February 2011

Cohen, R. L., \& Otterbein, N. 1992. The mnemonic effect of speech gestures: Pantomimic and non-pantomimic gestures compared. European Journal of RL Cohen - 1992

Ekman and Friesen .1972. Linguistics and gesture: an application of linguistic theory.Research Journal.

Goldin-Meadow, S. 2000. Beyond words: The importance of gesture to researchers and learners. Child Development, 71, 231-239.

James M.Clark \& Allan Paivio. 1991. Dual coding theory and education.Educational Psychology Review volume 3, pages149-210

James J. Asher. San Jose State College. Search for more papers by this ... First published: January 1969.

Karla K. Mc.Gregor. 2008. International Journal of Speech-Language Pathology 10(3):1127. June 2008 with 443.University of IOWA

Kendon, Adam. 1972. A review of "Kinesics and Context" by Ray L. Birdwhistell. American Journal of Psychology 85:441-455.

Quinn-Allen. 1995. conducted the first empirical study on the influence o and Engelkamp and Zimmer (1985) attributed the enhancement to the language in Gretchen $\mathrm{M}$. Reevy, - 2015 - Bursten .Stanley NPsychology

Tellier, M. 2005. How do teacher's gestures help young children in second language acquisition?. Research gate Publication.

Vanessa Van Edwards. 2017. Captivate: The Science of Succeeding with People Published April 25th 2017 by Portfolio 